\title{
Endoscopic ultrasound-guided gastrojejunostomy does not prevent pancreatico- duodenectomy after long-term symptom-free neoadjuvant treatment
}

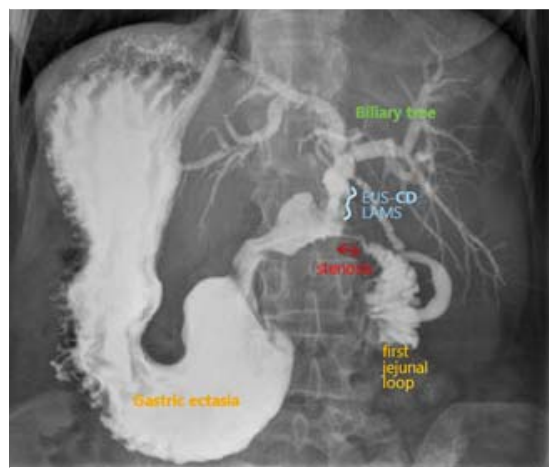

- Fig. 1 Gastrointestinal series showing gastric ectasia due to a short duodenal stenosis, with contrast accessing the biliary tree more easily through the lumenapposing metal stent. EUS-CD, endoscopic ultrasound-guided choledochoduodenostomy; LAMS, lumen-apposing metal stent.

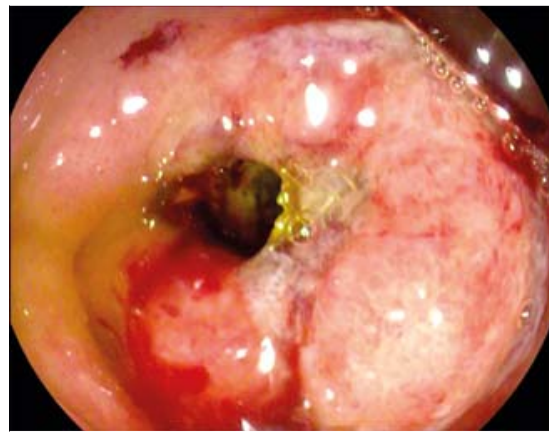

- Fig. 2 Endoscopic view of the duodenal infiltration of the bulb, with previous endoscopic ultrasound-guided choledochoduodenostomy lumen-apposing metal stent barely visible.

A 55-year-old woman was diagnosed with pancreatic head adenocarcinoma with hepatic artery and mesenteric vein contact. Due to cholangitis and papillary infiltration, an endoscopic ultrasound-guided choledochoduodenostomy (EUS-CD) was performed with an $8 \times 8$-mm electrocautery-enhanced lumen-apposing metal stent (LAMS; Hot Axios; Boston Scientific, Marlborough, Massachusetts, USA). One month later, she experienced gastric

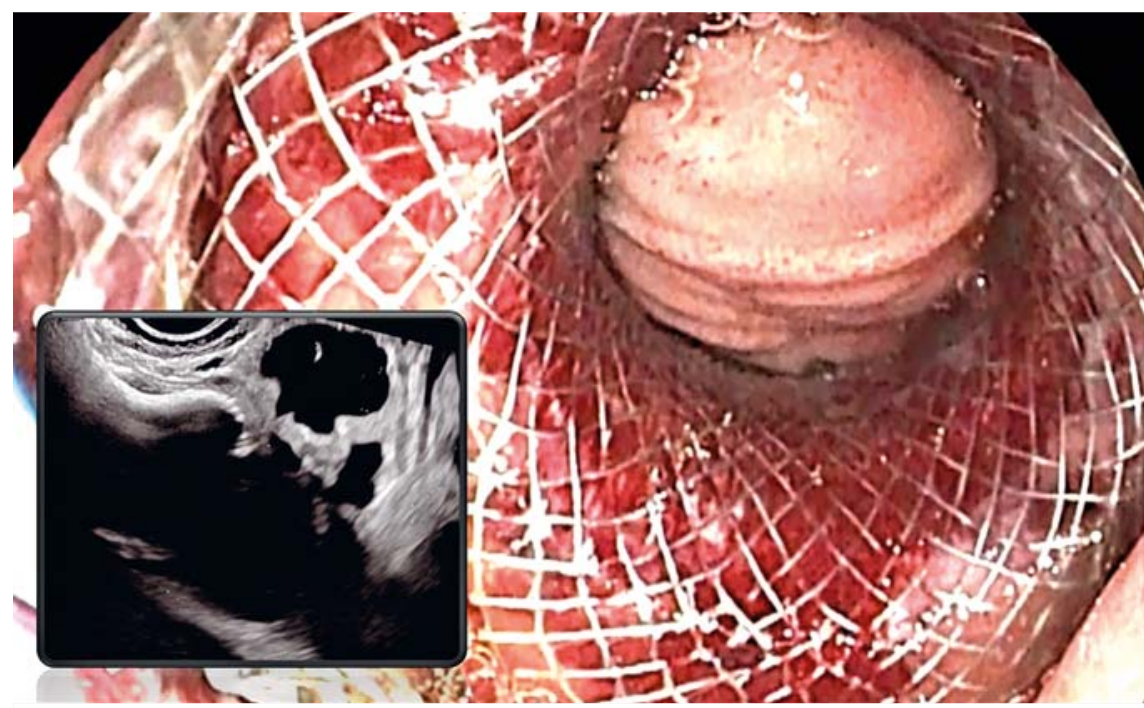

- Fig. 3 Endoscopic ultrasound-guided gastrojejunostomy using a 20-mm electrocauteryenhanced lumen-apposing metal stent.

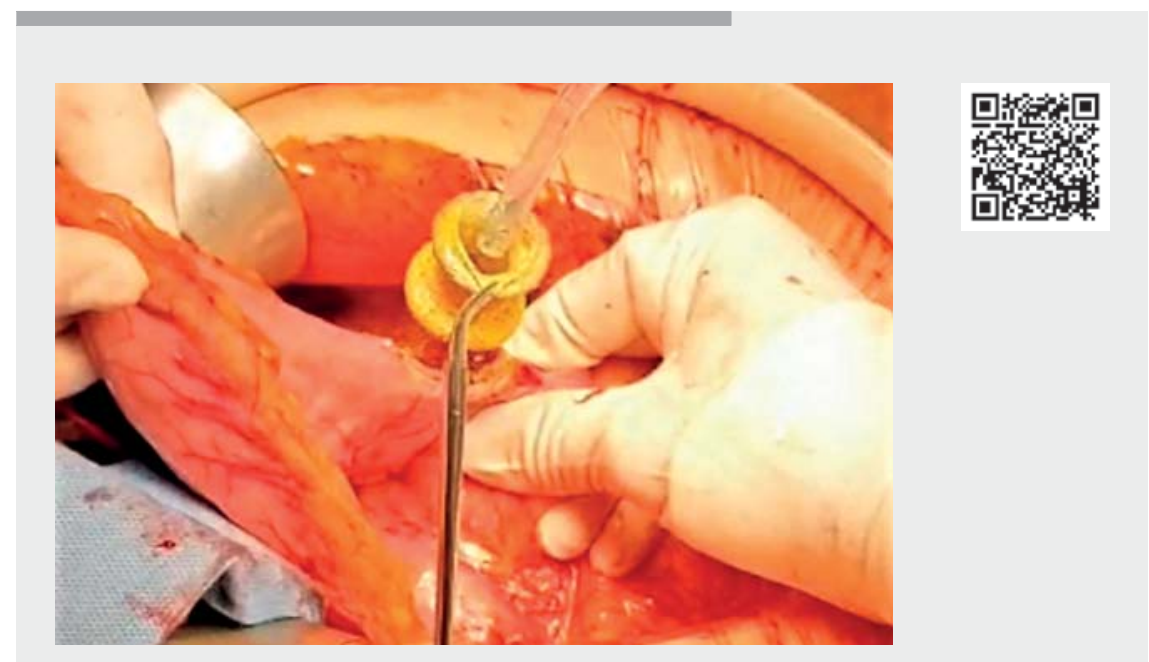

$\checkmark$ Video 1 Whipple resection after endoscopic ultrasound-guided gastrojejunostomy and choledochoduodenostomy.

outlet obstruction (GOO) secondary to duodenal infiltration ( $\triangleright$ Fig. 1).

Endoscopically, the former EUS-CD LAMS was barely visible due to neoplastic infiltration ( $\mathbf{F i g . 2}$ ). In order not to hinder biliary drainage, an EUS-guided gastrojejunostomy (EUS-GJ) was performed after fluid injection of the jejunum and freehand placement of a $20 \times 10-m m$ LAMS (Hot Axios), using wireless simplified (WEST) technique [1] ( $>$ Fig. 3).

The patient resumed feeding on postoperative day (POD) 1 and was discharged on POD 5. She started neoadju- 

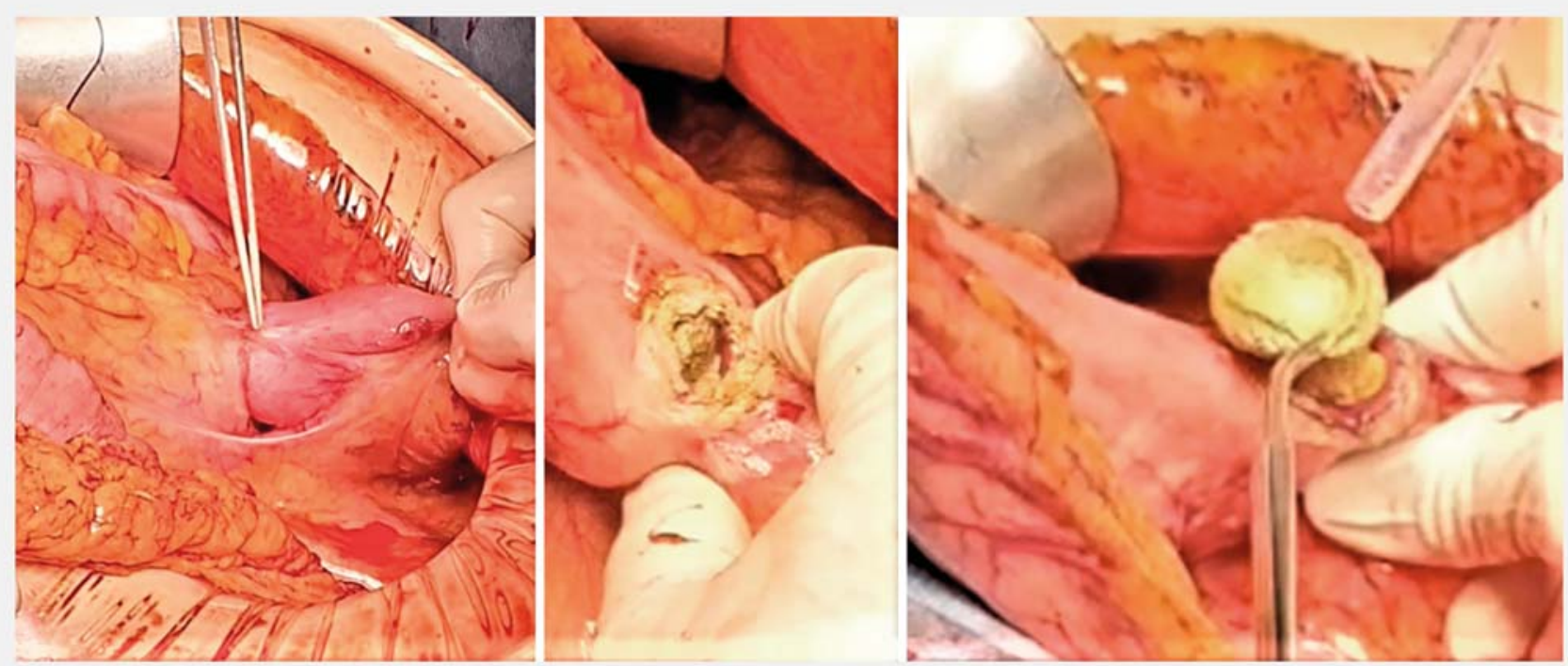

- Fig. 4 Surgical identification of the endoscopic ultrasound-guided gastrojejunostomy and removal of the lumen-apposing metal stent.
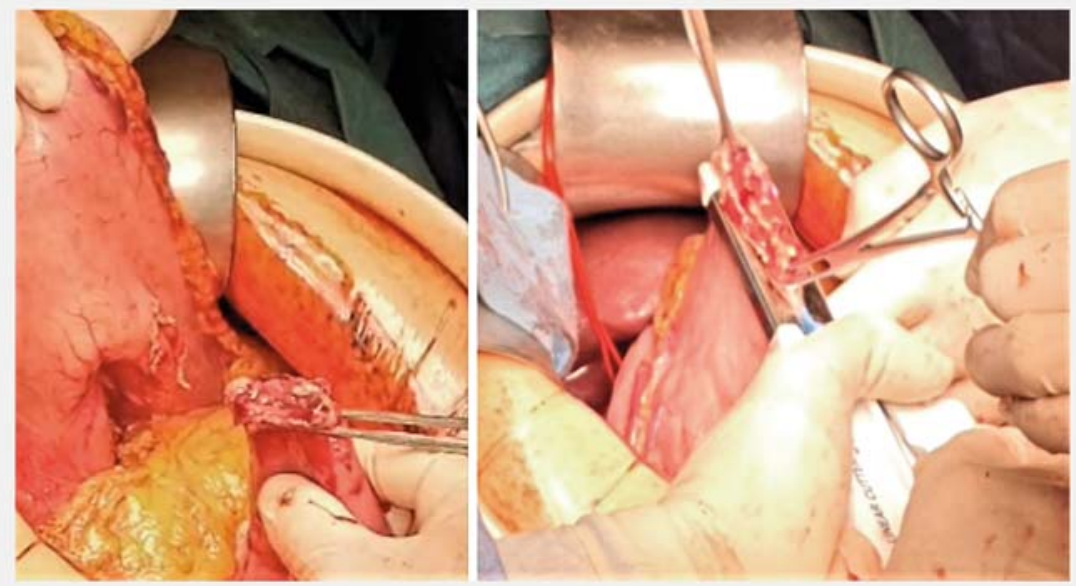

Fig. 5 Preparation of the jejunal loop for surgical anastomosis and closure of the gastrotomy using a stapler.

vant PAXG treatment (nab-paclitaxel, gemcitabine, capecitabine, cisplatin [2]) on POD 11. Computed tomography after 8 months showed significant regression of the lesion and its vascular contacts, and Whipple surgery was proposed after multidisciplinary discussion (\$Video 1 ). Surgical identification and disconnection of the EUS-GJ took no more than 20 seconds. The gastrojejunostomy site was cut on the central tract of the LAMS, and the stent was extracted ( $\mathbf{F i g . 4}$ ). The stomach was sutured using a linear-cutting stapler, the first jejunal loop was resected, and a termino-lateral gastrojejunos- tomy was performed ( $\triangleright$ Fig. 5). Hepaticojejunostomy was also not complicated by EUS-CD LAMS. Postoperative gastrointestinal series showed good gastric outlet and no contrast leakage. The patient was discharged after endoscopic management of one postoperative collection, and was feeling well after 96 days of follow-up.

While surgery after EUS-CD has been reported previously $[3,4]$, there is no published experience of pancreaticoduodenectomy following EUS-GJ. In this patient, EUS-CD $+G$ J provided 8 months free of jaundice and GOO and a rapid initiation of a neoadjuvant treatment, without affecting safety and oncological radicalism of subsequent surgery. Further evaluation of EUS-guided double bypass in the bridge-to-surgery scenario is therefore proposed.

Endoscopy_UCTN_Code_CPL_1AL_2AG

Competing interests

The authors declare that they have no conflict of interest.

The authors

Giuseppe Vanella ${ }^{1}$, Domenico Tamburrino², Giuseppe Dell'Anna', Maria Chiara Petrone', Stefano Crippa ${ }^{2}$, Massimo Falconi ${ }^{2}$, Paolo Giorgio Arcidiacono ${ }^{1}$

1 Pancreatobiliary Endoscopy and Endosonography Division, Pancreas Translational and Clinical Research Center, IRCCS San Raffaele Scientific Institute, Milan, Italy

2 Pancreatic Surgery Unit, Pancreas Translational and Clinical Research Center, IRCCS San Raffaele Scientific Institute, Milan, Italy 
Corresponding author

\section{Giuseppe Vanella, MD}

PancreatoBiliary Endoscopy and

Endosonography Division, Pancreas

Translational \& Clinical Research Center,

IRCCS San Raffaele Scientific Institute,

Vita-Salute San Raffaele University,

Via Olgettina 60, 20132, Milan, Italy

Phone: +390226439574

Fax: +390226435609

vanella.giuseppe@hsr.it

\section{References}

[1] Bronswijk M, Vanella G, Petrone MC et al. EUS-guided gastroenterostomy: less is more! The wireless EUS-guided gastroenterostomy simplified technique VideoGIE 2020 . 5: 442

[2] Reni M, Zanon S, Balzano G et al. A randomised phase 2 trial of nab-paclitaxel plus gemcitabine with or without capecitabine and cisplatin in locally advanced or borderline resectable pancreatic adenocarcinoma. Eur J Cancer 2018; 102: 95-102

[3] Fabbri C, Fugazza A, Binda C et al. Beyond palliation: using EUS-guided choledochoduodenostomy with a lumen-apposing metal stent as a bridge to surgery. a case series. J Gastrointest Liver Dis 2019; 28: 125-128

[4] Gaujoux S, Jacques ], Bourdariat R et al. Pancreaticoduodenectomy following endoscopic ultrasound-guided choledochoduodenostomy with electrocautery-enhanced lumen-apposing stents an ACHBT-SFED study. HPB 2021; 23: 154-160

Bibliography

Endoscopy 2022; 54: E143-E145

DOI 10.1055/a-1408-1180

ISSN 0013-726X

published online 16.4.2021

(c) 2021. Thieme. All rights reserved.

Georg Thieme Verlag KG, Rüdigerstraße 14, 70469 Stuttgart, Germany
ENDOSCOPY E-VIDEOS

https:/|eref.thieme.de/e-videos

口回 Endoscopy E-Videos is an

open access online section, 回: reporting on interesting cases and new techniques in gastroenterological endoscopy. All papers include a high quality video and all contributions are freely accessible online. Processing charges apply (currently EUR 375), discounts and wavers acc. to HINARI are available.

This section has its own submission website at

https://mc.manuscriptcentral.com/e-videos 